\title{
Influence of Manner Adverbs on Action Verb Processing
}

\author{
Jan Sieksmeyer, Anne Klepp, Valentina Niccolai, Jacqueline Metzlaff, \\ Alfons Schnitzler, and Katja Biermann-Ruben
}

\begin{abstract}
Language-motor interaction is suggested by the involvement of motor areas in action-related language processing. In a double-dissociation paradigm we aimed to investigate motor cortical involvement in the processing of hand- and foot-related action verbs combined with manner adverbs. In two experiments using different tasks, subjects were instructed to respond with their hand or foot following the presentation of an adverb-verb combination. Experiment 1, which prompted reactions via color changes of the stimuli combined with a semantic decision, showed an influence of manner adverbs on response times. This was visible in faster responses following intensifying adverbs compared with attenuating adverbs. Additionally, an interaction between implied verb effector and response effector manifested in faster response times for matching verb-response conditions. Experiment 2, which prompted reactions directly by the adverb type (intensifying vs. attenuating), revealed an interaction between manner adverbs and response effector with faster hand responses following intensifying compared with attenuating adverbs. Additional electroencephalography (EEG) recordings in Experiment 2 revealed reduced beta-desynchronization for congruent verb-response conditions in the case of foot responses along with faster response times. Yet, a direct modulation of verb-motor priming by adverbs was not found. Taken together, our results indicate an influence of manner adverbs on the interplay of language processing and motor behavior. Results are discussed with respect to embodied cognition theories.
\end{abstract}

Keywords Action-related language processing $\cdot$ Manner adverbs $\cdot$ Motor activity EEG

\footnotetext{
J. Sieksmeyer

Faculty of Natural Sciences, Institute of Experimental Psychology, Heinrich-Heine-Universität, Düsseldorf, Germany
}

\begin{abstract}
A. Klepp · V. Niccolai $(\bowtie) \cdot$ J. Metzlaff · A. Schnitzler $\cdot$ K. Biermann-Ruben Medical Faculty, Institute of Clinical Neuroscience and Medical Psychology, Heinrich-Heine-Universität, Düsseldorf, Germany e-mail: valentina.niccolai@hhu.de
\end{abstract}




\section{Introduction}

Embodied cognition theories propose that modal brain regions involved in perception and action are likewise involved in the processing and storage of semantic memory traces (Barsalou, 2008) as opposed to the classical view of amodal brain regions storing semantic memory traces in the form of symbols (for a review see Meteyard, Rodriguez Cuadrado, Bahrami, \& Vigliocco, 2012). Specifically, the motor component inherent to language containing action concepts triggers a simulation of the implied movement in sensorimotor areas which is likely reflected in increased activation (Kiefer \& Pulvermüller, 2011). The association between perceptual-motor and more cognitive brain areas can be explained through learning experiences, but the precise role of the re-activation of these areas during semantic processing is still under debate (Pulvermüller, 2018). For instance, it is important to elucidate in which detail semantic processing is supported by sensory-motor areas. This issue can be operationalized experimentally in different ways. The current study used adverb-verb combinations to modify the underlying action concept during verbal processing. Behavioral and neurophysiological data were examined in order to find possible interactions of adverbial context with verb processing. These interactions would argue for the contribution of motor cortical areas to language processing being specific and detailed, going beyond superficial epiphenomena.

In turn, theories of language and semantic processing are continuously revised to accommodate empirical findings concerning the functional and neuroanatomical grounding of semantic memory in modality-specific areas (Barsalou, 2008; Binder \& Desai, 2011; Pulvermüller, 2018). The current study was aimed at contributing to this discussion by investigating one aspect of embodied cognition, namely the potential interaction between action verb processing and a modifying adverb.

Previous studies reported motor activation either during language processing of action sentences (Aziz-Zadeh, Wilson, Rizzolatti, \& Iacobini, 2006; Boulenger, Hauk, \& Pulvermüller, 2009; de Vega, Léon, Hernández, Valdés, Padrón, \& Ferstl, 2014; Tettamanti et al., 2005) or action verbs (Hauk, Johnsrude, \& Pulvermüller, 2004; Kemmerer, Castillo, Talavage, Patterson, \& Wiley, 2008; Yang \& Shu, 2011). Motor activation seems to be somatotopical in the sense that action verbs implying the movement of a specific extremity elicit activation in corresponding cortical motor areas (Hauk et al., 2004; Pulvermüller, 2005). On the other hand, another study reported no somatotopical activation in primary and premotor areas but rather found action-related activation in the pre-SMA potentially holding an abstract representation of the action verbs in the form of instructional cues (Postle, McMahon, Ashton, Meredith, \& de Zubicaray, 2008).

On behavioral level, an interaction between action-related language processing and motor execution emerged in altered kinematic measures (Boulenger, Roy, Paulignan, Deprez, Jeannerod, \& Nazir, 2006; Dalla Volta, Gianelli, Campione, \& Gentilucci, 2009) and in reaction time (Buccino, Riggio, Melli, Binkofski, Gallese, \& Rizzolatti, 2005; Sato, Mengarelli, Riggio, Gallese, \& Buccino, 2008). Conversely, motor output was shown to affect action language processing (Rüschemeyer, 
Lindemann, van Rooij, van Dam, \& Bekkering, 2010). Depending on the task and stimulus timing both facilitation (Andres, Finocchiaro, Buiatti, \& Piazza, 2015; Glenberg \& Kaschak, 2002; Klepp et al., 2017; Scorolli \& Borghi, 2007) and interference or prolongation (Boulenger et al., 2006; Klepp, Niccolai, Buccino, Schnitzler, \& Biermann-Ruben, 2015; Sato et al., 2008) of motor behavior (i.e. response times) were found.

The demonstrable engagement of motor areas is also evident in studies showing an impairment of action-related language processing in patients suffering from Parkinson's Disease (Fernandino et al., 2013; Herrera, Rodríguez-Ferreiro, \& Cuetos, 2011) and Amyotrophic Lateral Sclerosis (Bak, O’Donovan, Xuereb, Boniface, \& Hodges, 2001; Grossmann et al., 2008). These impairments indicate an initially important role of motor areas in the ontogenesis of language acquisition (Perniss \& Vigliocco, 2014), while neurological disorders affecting motor areas seem to impede an efficient and complete access to semantic memory traces in later life. This can, however, be still partly compensated for by other brain areas (Pulvermüller, 2018). Yet, these results suggest a substantial contribution of motor areas to action-related language processing.

Aside from somatotopy, there is further evidence that sensorimotor involvement in language processing is specific and detailed. For instance, it may reflect semantic features of verbal material: The amount of effector-specific movement affected verbmotor priming (Klepp et al., 2017). Additionally, functional magnetic resonance imaging $(f M R I)$ activity in parietal areas within the motor network was modulated by the specificity of action plans described by verbs (van Dam, Rüschemeyer, \& Bekkering, 2010). Activity in pre-motor areas can reflect motor features described in action sentences, e.g. the degree of physical effort the described action requires as determined by a verb-object combination (Moody \& Gennari, 2010).

In natural language, however, important cues about the precise implied action may not only come from the verb itself, but from other sources such as objects and adverbial constructions. The linguistic focus hypothesis $(L F H)$ postulated by Taylor and Zwaan (2008) suggests that motor simulation, which is assumed in the theoretical framework of embodied cognition theories regarding action-related language processing, is dependent on the linguistic focus. If the described action is maintained within the linguistic focus, e.g. through action-modifying adverbs, motor simulation of the action occurs beyond the action verb itself and continuation of motor activity should be observed; if the linguistic focus is shifted away from the action, e.g. through agent-modifying adverbs, no motor simulation occurs and termination of motor activity should be observed. The study conducted by Taylor and Zwaan (2008) demonstrated that adverbs can influence reading times. Participants were instructed to read a sentence frame by frame by turning a knob either in clockwise or counter-clockwise direction. The sentences contained hand action verbs depicting either clockwise or anticlockwise movements followed by an adverb either modifying the action (e.g. quickly) or the agent (e.g. happily). Facilitation of reading times occurred in direction-matching versus non-matching verb-response conditions and when adverbs modified the action instead of the agent. 
Yet it remains unclear, if the motor simulation of the action verb is differentially affected by different kinds of adverbs. For example, despite relating to a bodily action, action verbs might not contain lexically specific information about the amount of force with which the action is executed (Goldschmidt, Gamerschlag, Petersen, Gabrovska, \& Geuder, 2017). This questionnaire study examined whether the force component in the German action verb "schlagen" (to hit) could be modulated in sentences containing adverbs. Crucially, force-denoting manner adverbs (lightly/hard) directly modified the action's force component in the direction suggested by the adverb. Moreover, force modification may also be achieved by inferences through agent-oriented adverbs (Goldschmidt et al., 2017). The current study uses manner adverbs denoting a clear attenuation or intensification of either the force component or the speed component, thus expected to directly modify the action described by verbs. Note that the term "force" is used as a synonymous expression for "intensity" and is not used in terms of causality, as it is in the linguistic field of "force semantics" and "force dynamics".

Based on these findings we investigated in two separate experiments if adverbs further influence reaction times in a well-established priming paradigm containing hand/foot action verbs and hand/foot responses (Klepp et al., 2017). In both experiments, the interaction of verb type and response effector was anticipated as a priming effect resulting in faster response times for congruent verb-response conditions. We furthermore introduced intensifying and attenuating manner adverbs as an additional factor. The previously observed interaction of verb type and response effector was hypothesized to be more pronounced when the action verb was combined with an intensifying compared to an attenuating adverb resulting in even faster response times in congruent verb-response conditions. Adverb-verb (Experiment 1) and verb-adverb (Experiment 2) order of presentation realized in two separate experiments additionally allowed investigating the influence of the time point of adverb presentation with respect to the action verb processing stream.

A useful technique to investigate the time course of activation with respect to action verb processing is EEG. Increased activity in motor areas is typically accompanied by increased desynchronization in the mu $(10-15 \mathrm{~Hz})$ and the beta band (15-25 Hz). This oscillatory pattern is generally associated with motor preparation and execution (Pfurtscheller \& Lopes da Silva, 1999; Pfurtscheller, Neuper, Andrew, \& Edlinger, 1997). Typically, desynchronization increases, reaching a peak during response execution, while a rebound consisting in increased synchronization is found about a second after movement offset (Pfurtscheller, \& Lopes da Silva, 1999). A similar pattern has also been observed during action verb processing (van Elk, van Schie, Zwaan, \& Bekkering, 2010; Moreno, de Vega, Léon, Bastiaansen, Lewis, \& Magyari, 2015; Niccolai, Klepp, Weissler, Hoogenboom, Schnitzler, \& BiermannRuben, 2014). Neural oscillatory and event-related potential (ERP) effects related to the presentation of action verbs have been reported as early as 170-250 ms after word onset (Pulvermüller, Härle, \& Hummel, 2000, 2001; van Elk et al., 2010), displaying somatotopy (Hauk et al., 2004; Pulvermüller et al., 2001). This pattern of results suggests that motor areas contribute to the processing of verbal linguistic action stimuli. 
We therefore conducted EEG measurements in Experiment 2 to gain further insights in the processing of the action verb and its possible interaction with the adverb. According to the somatotopic organization of the motor cortex, differential effects for hand and foot responses were hypothesized in electrode sites C3 and $\mathrm{Cz}$, respectively. We expected stronger hand-related activity at electrode site $\mathrm{C} 3$ and stronger foot-related activity at electrode site $\mathrm{Cz}$. This approach has been successfully used regarding evoked EEG activity during action verb reading before (Hauk \& Pulvermüller, 2004; Pulvermüller et al., 2000, 2001). We specifically focused on the mu and beta band in our study due to their role in motor processes (Pfurtscheller \& Lopes da Silva, 1999) and action-related language processing (Klepp et al., 2015, Moreno et al., 2015; van Elk et al., 2010). Thus, we expected the mu and beta desynchronization around the onset of the response to be reduced in congruent conditions due to the priming effect of the action verbs (Grisoni, Dreyer, \& Pulvermüller, 2016; Schacter, Wig, \& Stevens, 2007).

As the manner adverb directly modified the action verb which elicits motor activity if semantically processed, we expected the adverb to further modulate the language-motor interaction. The interaction of verb type and response effector was hypothesized to be more pronounced when the action verb was combined with an intensifying compared to an attenuating adverb, resulting in reduced mu and beta desynchronization in congruent verb-response conditions.

Methods and Results of Experiments 1 and 2 will be reported separately followed by a joint discussion.

\section{Experiment 1}

\subsection{Methods}

\subsubsection{Participants}

Thirty-two participants (eleven male; mean age $=24.97$ years, $S D=6.71$ ) were included into the study. Exclusion criteria were academic linguistic expertise, history of prior neurological or psychiatric disorders and medication affecting the central nervous system. Participants were monolingual German native speakers with normal or corrected-to-normal vision. Right-handedness and footedness was assessed and confirmed. Hand dominance was assessed with the Hand Dominance Test (HDT, Steingrüber, 2011), as well as with the German version of the Edinburgh Handedness Questionnaire (EHI, Oldfield, 1971). Right footedness was tested with a self-report questionnaire extracted from the Lateral Preference Inventory (LPI, Ehrenstein \& Arnold-Schulz-Gahmen, 1997).

This experiment is in accordance with the Declaration of Helsinki and was approved by the ethics committee of the Medical Faculty at Heinrich-HeineUniversity Düsseldorf (study number: 3400). All subjects gave written informed 
consent before the beginning of the experiment and received course credit or financial reimbursement.

Two subjects were excluded due to data loss. Three subjects exceeded our criterion of at most $10 \%$ incorrect responses during the experiment. After the experimental session, one participant reported taking medication affecting the central nervous system and was also excluded. The final set of participants in Experiment 1 therefore consisted of 26 subjects (nine male, mean age $=25.28$ years, $S D=7.39$ ).

\subsubsection{Stimuli}

We used a total of 36 disyllabic German verbs and eight German adverbs (for an overview see Table 1). The verb set consisted of three categories with 12 verbs each: manual actions, e.g. "klatschen" (to clap), foot actions, e.g. "rennen" (to run) and abstract actions, e.g. "denken" (to think). We used a subset of verbs out of a previous selection which had been based on successive rating and matching procedures (details see Klepp et al., 2014) including familiarity, imageability and movement energy, as well as word length and verb frequency (Leipzig Corpora Collection, LCC, Biemann, Heyer, Quasthoff, \& Richter, 2007, available at http://wortschatz.uni-leipzig.de). As indicated by a multivariate ANOVA with verb category as an independent variable the final set of verbs differed with regard to some of these variables, but only in comparison to the abstract verb category. This category served as the No Go-condition, however and was not further analyzed. Importantly, hand and foot verbs did not differ significantly (all $p>0.087$ ).

Twenty-five adverbs entered a rating process $(n=4)$ serving to redefine stimuli selection. Participants were asked to evaluate the probability of verb and adverb going together (from "not at all" to "absolutely"). This was termed as the semantic fit of adverb-verb combinations. Adverb selection was based on their semantic fit with the previously selected set of action verbs, as well as the possibility to define opposed pairs of intensifying and attenuating adverbs, e.g. "kräftig"_- "kraftlos" (strongly_ feebly). This resulted in the subsequent inclusion of eight out of the initially selected 25 adverbs, four of which strengthening or accelerating the movement implied by the verb (intensifying adverbs) and four weakening or slowing the implied action (attenuating adverbs). Exact Mann-Whitney- $U$-Test revealed no significant differences in the frequency of intensifying and attenuating adverbs $(U=14.50, p=0.343)$ nor differences in their semantic fit to hand verbs $(U=6.50, p=0.645)$ or foot verbs $(U=5.00, p=0.381)$, respectively. Please note that linguistically all adverbs are adjectives applied in an adverbial manner of use. For the sake of simplification we will refer to them as "manner adverbs" in this article.

\subsubsection{Procedure}

Subjects were seated at a distance of $95 \mathrm{~cm}$ from a computer screen (ASUS VG248, ASUS Computer International, Fremont, California, USA) with a keyboard in front 
Table 1 The stimulus set consisted of 36 verbs and 8 adverbs. All adverbs and verbs are reported in German and English, respectively, although only the German version was used in the study

\begin{tabular}{|c|c|c|c|}
\hline Verb category & Hand & Foot & Abstract \\
\hline & $\begin{array}{l}\text { boxen } \\
\text { (to box })\end{array}$ & \begin{tabular}{|l} 
hinken \\
(to limp $)$
\end{tabular} & \begin{tabular}{|l} 
achten \\
(to respect)
\end{tabular} \\
\hline & $\begin{array}{l}\text { fuchteln } \\
\text { (to flail) }\end{array}$ & $\begin{array}{l}\text { humpeln } \\
\text { (to hobble) }\end{array}$ & $\begin{array}{l}\text { ahnen } \\
\text { (to guess) }\end{array}$ \\
\hline & $\begin{array}{l}\text { klatschen } \\
\text { (to clap) }\end{array}$ & $\begin{array}{l}\text { kicken } \\
\text { (to kick) }\end{array}$ & $\begin{array}{l}\text { büßen } \\
\text { (to atone) }\end{array}$ \\
\hline & $\begin{array}{l}\text { kneten } \\
\text { (to knead) }\end{array}$ & $\begin{array}{l}\text { laufen } \\
\text { (to walk) }\end{array}$ & $\begin{array}{l}\text { denken } \\
\text { (to think) }\end{array}$ \\
\hline & $\begin{array}{l}\text { paddeln } \\
\text { (to paddle) }\end{array}$ & \begin{tabular}{|l} 
rennen \\
(to run)
\end{tabular} & $\begin{array}{l}\text { gönnen } \\
\text { (to indulge) }\end{array}$ \\
\hline & $\begin{array}{l}\text { rubbeln } \\
\text { (to rub) }\end{array}$ & \begin{tabular}{|l|} 
schlittern \\
(to slide)
\end{tabular} & $\begin{array}{l}\text { grübeln } \\
\text { (to ponder) }\end{array}$ \\
\hline & $\begin{array}{l}\text { scheuern } \\
\text { (to scourn) }\end{array}$ & $\begin{array}{l}\text { schlurfen } \\
\text { (to shuffle) }\end{array}$ & $\begin{array}{l}\text { hoffen } \\
\text { (to hope) }\end{array}$ \\
\hline & $\begin{array}{l}\text { schrubben } \\
\text { (to scrub) }\end{array}$ & \begin{tabular}{|l} 
stampfen \\
(to stamp)
\end{tabular} & $\begin{array}{l}\text { merken } \\
\text { (to remember) }\end{array}$ \\
\hline & $\begin{array}{l}\text { stupsen } \\
\text { (to nudge) }\end{array}$ & $\begin{array}{l}\text { strampeln } \\
\text { (to struggle) }\end{array}$ & $\begin{array}{l}\text { träumen } \\
\text { (to dream) }\end{array}$ \\
\hline & $\begin{array}{l}\text { tippen } \\
\text { (to type) }\end{array}$ & $\begin{array}{l}\text { tänzeln } \\
\text { (to prance) }\end{array}$ & $\begin{array}{l}\text { wünschen } \\
\text { (to wish) }\end{array}$ \\
\hline & $\begin{array}{l}\text { trommeln } \\
\text { (to drum) }\end{array}$ & $\begin{array}{l}\text { trampeln } \\
\text { (to tramp) }\end{array}$ & $\begin{array}{l}\text { wundern } \\
\text { (to marvel) }\end{array}$ \\
\hline & $\begin{array}{l}\text { zupfen } \\
\text { (to pick) }\end{array}$ & $\begin{array}{l}\text { treten } \\
\text { (to tread })\end{array}$ & \begin{tabular}{|l} 
zweifeln \\
(to doubt)
\end{tabular} \\
\hline
\end{tabular}

\begin{tabular}{l|l|l}
\hline Adverb category & Intensifying & Attenuating \\
\hline \multirow{2}{*}{} & kräftig (forcefully) & kraftlos (feebly) \\
\cline { 2 - 3 } & hektisch (hectically) & ruhig (calmly) \\
\cline { 2 - 3 } & stark (strongly) & zaghaft (tentatively) \\
\cline { 2 - 3 } & flink (swiftly) & träge (dully) \\
\hline
\end{tabular}

of them and a foot pedal (USB Triple Foot Switch II; Scythe, Tokyo, Japan) positioned under the table. All trials started with a black background screen containing a white fixation cross at the center presented for $1200 \mathrm{~ms}$. This was followed by the presentation of a mask consisting of two horizontal lines of seven white ' $X$ ' for a jittered interval between 400 and $700 \mathrm{~ms}$. Thereafter, an adverb was presented in white letters pseudorandomly above or below the fixation cross for $400 \mathrm{~ms}$ together with the remaining upper or lower line of seven ' $X$ '. The verb followed in white letters replacing the latter seven ' $\mathrm{X}$ ' and the adverb-verb combination was displayed together for another $400 \mathrm{~ms}$. Then, the stimuli turned either blue or yellow. Subjects were instructed to respond as fast and accurately as possible with the hand or the foot according to the color of the adverb-verb combination, but only if the verb expressed 


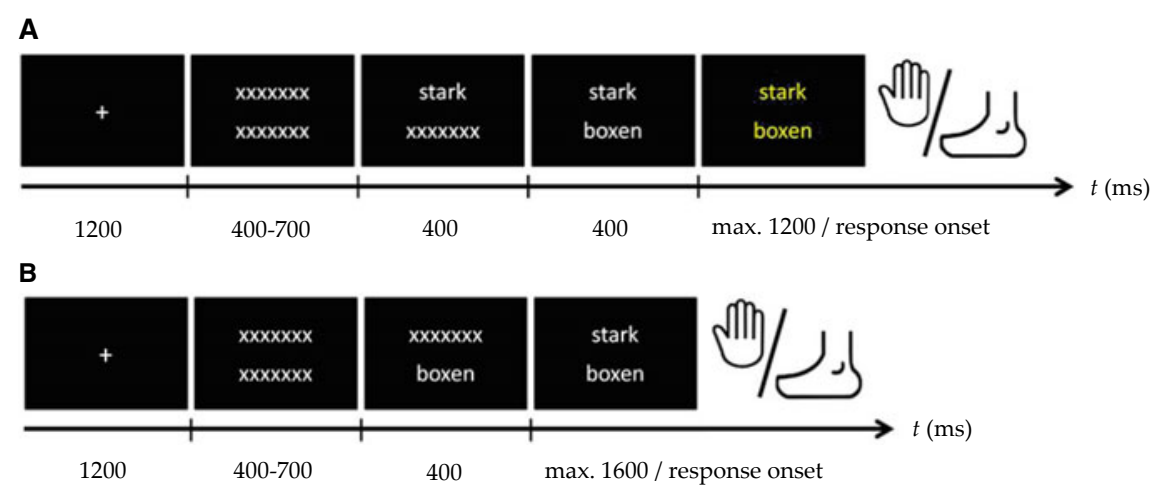

Fig. 1 Experimental procedure. A Experiment 1. B Experiment 2

a concrete bodily action. Participants were pseudorandomly assigned to one of two groups of color change instructions: color change to blue required a hand response by pressing the 'space'-key on a keyboard while a color change to yellow required a foot response by pressing down a foot pedal for $50 \%$ of the subjects. For the other $50 \%$, the assignment was reversed. The experimental procedure of each trial is shown in Fig. 1A.

Pseudorandomization of the spatial position of verb and adverb was introduced to prevent participants from adopting a strategy to solely attend to the stimulus relevant for solving the experimental task, i.e. the verb in Experiment 1 and the adverb in Experiment 2, respectively. The spatial predictability of these stimuli could have resulted in impaired semantic processing of adverb-verb-combinations, which we tried to preclude by variation of the spatial positions.

Each adverb was combined with each verb and presented once with each type of color change resulting in a total of 576 trials per subject. The experiment lasted about 50 min. Stimuli were presented using Presentation 14.9 software (Neurobehavioral Systems, Albany, California, USA).

\subsubsection{Statistical Analysis}

We computed a linear mixed effect model using the package lme4 (version 1.1-13, Bates, Maechler, Bolker, \& Walker, 2015) for R (version 3.3.3) including crossed random effects for subjects and items. This method is especially advantageous for studies incorporating psycholinguistic stimuli since it is assumed that not only participants but also the items are randomly drawn from a population (Baayen, Davidson, \& Bates, 2008). Linear mixed effect models allowed the inclusion of the two-level factor verb (hand, foot), the two-level factor adverb type (intensifying, attenuating) and the two-level factor response effector (hand response, foot response). Thus, the fixed effects included the factors verb, adverb type and response effector, as well as their two-way and three-way interactions. Random effects for 
participants included random intercepts with random slopes for the factors verb, adverb type and response effector. Random effects for items only included random intercepts. All analyses used logarithmically transformed reaction times of correct responses within 150 to $1500 \mathrm{~ms}$. $T$-values below -2 or above 2 are considered to represent significant effects. Post hoc tests were calculated using the package lsmeans (version 2.25-5, Lenth, 2016).

\subsection{Results}

\subsubsection{Behavioral Data}

Errors and responses faster than $150 \mathrm{~ms}$ or slower than $1500 \mathrm{~ms}$ after the Go-signal onset were excluded resulting in the exclusion of 358 trials (3.59\%). The Go-signal is defined as the cue stimulus prompting a response, i.e. here the color change of the adverb-verb-combination. Raw data are shown in Fig. 2A. We observed a significant main effect of response effector $(t=4.86)$ with faster hand responses than foot

A

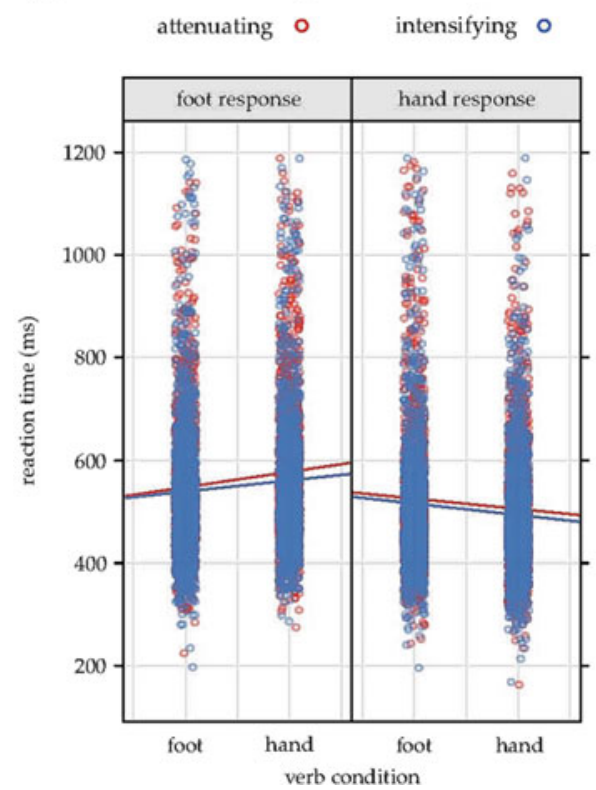

B $\quad$ Experiment 2 attenuating $\circ \quad$ intensifying $\circ$

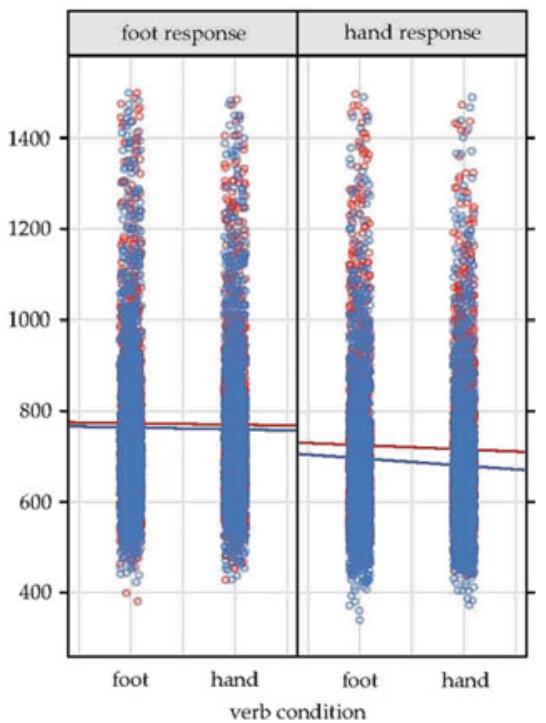

Fig. 2 Data distribution in Experiment 1 (A) and Experiment 2 (B). Raw data is split for verb conditions (hand verb, foot verb) on the $\mathrm{x}$-axis, $\mathrm{y}$-axis indicates the response times in milliseconds. Data is furthermore split according to the response effector (hand responses, foot responses) following intensifying (blue) and attenuating (red) adverbs. Red and blue lines indicate mean values in the respective conditions 
responses. The main effect of adverb type was significant $(t=4.01)$ as well, with faster responses following intensifying adverbs compared to attenuating adverbs. Furthermore, the interaction between verb and response effector was significant $(t$ $=-11.20)$. Post hoc tests indicated significantly faster $(z=3.25, p=0.001)$ hand responses following hand verbs compared to foot verbs and significantly faster $(z=$ $-3.76, p<0.001$ ) foot responses following foot verbs compared to hand verbs. The hypothesized three-way interaction of verb, response effector and adverb type was not significant $(t=-0.32)$. All model estimates are given in Table 2. Fitted model parameters $( \pm S D)$ for verb $\mathrm{x}$ adverb type $\mathrm{x}$ response effector are depicted in Fig. 3A.

Table 2 Results of statistical analyses of behavioral data. Model estimates $(\beta)$, standard error (SE) and $t$-values are reported for Experiment 1 (left) and Experiment 2 (right). Significant effects are bold

\begin{tabular}{l|r|l|r|r|l|r}
\hline & \multicolumn{4}{|l|}{ Experiment 1} & \multicolumn{4}{l}{ Experiment 2} \\
\cline { 2 - 8 } & \multicolumn{1}{l|}{$\beta$} & \multicolumn{1}{l}{$S E$} & \multicolumn{1}{l}{$t$} & \multicolumn{1}{l}{$\beta$} & \multicolumn{1}{l}{$S E$} & \multicolumn{1}{l}{} \\
\hline Verb & -0.002 & 0.006 & -0.27 & 0.005 & 0.003 & 1.63 \\
\hline Adverb type & $\mathbf{0 . 0 1 0}$ & $\mathbf{0 . 0 0 2}$ & $\mathbf{4 . 0 1}$ & 0.017 & 0.010 & 1.66 \\
\hline Response effector & $\mathbf{0 . 0 4 5}$ & $\mathbf{0 . 0 0 9}$ & $\mathbf{4 . 8 6}$ & $\mathbf{0 . 0 4 4}$ & $\mathbf{0 . 0 0 8}$ & $\mathbf{5 . 6 5}$ \\
\hline Verb x adverb type & -0.002 & 0.002 & -1.03 & -0.001 & 0.002 & -0.79 \\
\hline Verb x response effector & $\mathbf{- 0 . 0 2 3}$ & $\mathbf{0 . 0 0 2}$ & $\mathbf{- 1 1 . 2 0}$ & -0.003 & 0.002 & -1.70 \\
\hline Adverb type x response effector & 0.001 & 0.002 & 0.47 & $\mathbf{- 0 . 0 0 9}$ & $\mathbf{0 . 0 0 2}$ & $\mathbf{- 4 . 6 8}$ \\
\hline Verb x adverb type x response effector & -0.001 & 0.002 & -0.32 & 0.002 & 0.002 & 0.82 \\
\hline
\end{tabular}
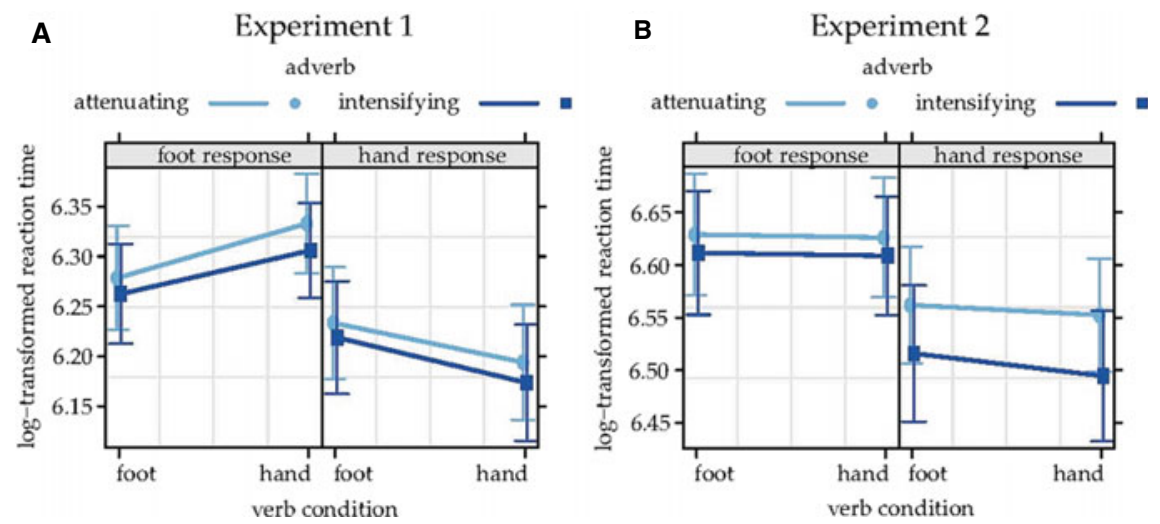

Fig. 3 Effects of Experiment 1 (A) and Experiment 2 (B). The 2-level factor verb (hand verb, foot verb) is denoted on the $\mathrm{x}$-axis, $\mathrm{y}$-axis indicates log-transformed response times. Data are split according to adverb type (intensifying adverb, attenuating adverb) and response effector. Circles, squares and error bars indicate fitted model parameters with standard deviation 


\section{Experiment 2}

\subsection{Methods}

\subsubsection{Participants}

Seventeen participants ( six male; mean age $=24.82$ years, $S D=4.90$ ) were included into the study. Exclusion criteria were the same as in Experiment 1. Handedness and footedness was assessed as in Experiment 1. The experiment is in accordance with the Declaration of Helsinki and was approved by the ethics committee of the Medical Faculty at Heinrich-Heine-University Düsseldorf (study number: 3400). All subjects gave written informed consent before the beginning of the experiment and received course credit or financial reimbursement.

Two subjects were excluded due to unidentifiable artifacts in the EEG recordings and excessive eye blinks during stimulus presentation. The final set of participants in Experiment 2 consisted of 15 subjects ( 1 ix male, mean age $=24.93$ years, $S D=$ 5.23).

\subsubsection{Stimuli}

The stimulus set included the same adverbs and concrete verbs as in Experiment 1, i.e. 24 concrete verbs (twelve hand verbs and twelve foot verbs) and eight adverbs (four intensifying adverbs, four attenuating adverbs).

\subsubsection{Procedure}

All subjects participated in two separate experimental sessions at least seven days apart. Sessions differed regarding the instructions: in one session subjects had to react with their right hand to intensifying adverbs and with their right foot to attenuating adverbs. Reaction times were recorded. The response effector-adverb type relationship was reversed in the other session. The order of sessions was counterbalanced across subjects. Experimental sessions were conducted in an electrically shielded room. The experimental setup was the same as described in Experiment 1 with only few changes. First, the verb preceded the adverb. Second, the onset of the adverb instantaneously cued the response effector according to the respective instructions of the current session, i.e. there was no color change. Third, the verb-adverb combination was presented until response onset or maximally $1600 \mathrm{~ms}$. The trial design is depicted in Fig. 1B. Each adverb was paired with each verb and each combination was shown twice, thus resulting in a total of 384 trials per subject. Each experimental session lasted about 30 min. Stimuli were presented using Presentation 14.9 software (Neurobehavioral Systems, Albany, California, USA) in white font on a black background. 


\subsubsection{EEG Data Acquisition}

We recorded the EEG signal with $29 \mathrm{Ag}-\mathrm{AgCl}$ electrodes mounted in an elastic cap (EASYCAP GmbH, Herrsching, Germany), according to the 10/20 system. The average of right and left mastoid was used as reference and electrode position $\mathrm{AFz}$ as ground. Vertical EOG was recorded using bipolar electrodes. EEG-signals were amplified with a BrainAmp MR Plus amplifier (Brain Products, Munich, Germany). A sampling rate of $1000 \mathrm{~Hz}$ and an online high-pass filter of $0.3 \mathrm{~Hz}$ were applied. Impedance of all electrodes was kept below $10 \mathrm{k} \Omega$. EEG and EOG signals were registered with BrainVision Recorder (Brain Products GmBH, Munich, Germany).

\subsubsection{EEG Data Processing}

Neurophysiological data were analyzed with Fieldtrip (version 20160629, Oostenveld, Fries, Maris, \& Schoffelen, 2011), an open source toolbox for Matlab (version R2016a, Mathworks, Natick, Massachusetts, USA). Episodes include time-windows from $2 \mathrm{~s}$ before verb onset to $0.5 \mathrm{~s}$ after response onset. A semi-automatic artifact detection routine was applied to identify electrode jumps and muscle artifacts. A lowpass filter at $120 \mathrm{~Hz}$ was applied and line noise at 50 and $100 \mathrm{~Hz}$ filtered out. Trials were visually inspected for blink artifacts in the critical time window between verb and response onset as well as for non-EOG artifacts in the whole trial. Trials containing artifacts were rejected. Remaining blink artifacts in the baseline or post-response period were removed using independent component analysis (ICA).

Data were subsequently split into eight conditions defined by adverb type (intensifying vs. attenuating), verb (hand vs. foot) and response effector (hand vs. foot) and entered a time-frequency analysis. To discern and investigate semantic processing around adverb onset and motor processes during response execution more closely, we conducted two analyses locked to adverb and response onset, respectively. In both analyses data were aligned to the respective event, with 0 either denoting the onset of adverb or response. Time-frequency representations (TFRs) were computed in steps of $2 \mathrm{~Hz}$ from 2 to $30 \mathrm{~Hz}$ using a Fourier transformation. We applied a single Hanning taper with a width of 5 cycles, sliding in steps of $40 \mathrm{~ms}$. Data were baseline-corrected using a time window of $t_{a}=-1.3$ to $-0.8 \mathrm{~s}$ for the adverb-locked analysis and $t_{r}=$ -1.5 to $-1.0 \mathrm{~s}$ for the response-locked analysis.

\subsubsection{Statistical Analysis}

\section{Behavioral Data}

The linear mixed effect model contained the two-level factors verb (hand, foot), adverb type (intensifying, attenuating) and response effector (hand response, foot response). Fixed effects included the factors verb, adverb and response and their interactions. Random effects for participants included random intercepts for subjects 
and random slopes for the factors verb, adverb and response. Random effects for items only included random intercepts. Logarithmically transformed reaction times of correct responses within 150 to $1500 \mathrm{~ms}$ entered the analysis. $T$-values below -2 or above 2 are considered to represent significant effects. Post hoc tests were carried out using the package lsmeans (version 2.25-5, Lenth, 2016).

\section{EEG Data}

To statistically analyze the EEG data we computed pseudo- $t$-values for each participant to normalize individual differences (compare Lange, Oostenveld, \& Fries, 2011). These $t$-values were then transformed into $z$-values to account for different number of trials in each condition (Klepp et al., 2015; see van Dijk, Nieuwenhuis, \& Jensen, 2010). Then we applied a non-parametric statistical procedure to assess significant differences on the group level. This non-parametric randomization approach identifies clusters containing neighboring timepoints and frequencies while simultaneously correcting for multiple comparisons (Maris \& Oostenveld, 2007).

Conditions were considered significantly different if the test statistic obtained from 5000 permutations resulted in an alpha-level below 0.05 . We defined the relevant contrasts of conditions based on the resulting significant behavioral effects. In addition, we investigated if semantic priming is mirrored in reduced desynchronization in congruent verb-response conditions, as stated in our hypothesis. Electrodes $\mathrm{C} 3$ as proxy of the right hand and $\mathrm{Cz}$ as proxy of the right foot were analyzed separately.

\subsection{Results}

\subsubsection{Behavioral Data}

Errors and responses faster than $150 \mathrm{~ms}$ or slower than $1500 \mathrm{~ms}$ after adverb onset were excluded from further analysis resulting in the exclusion of 411 trials $(3.57 \%)$. Raw data are shown in Fig. 2B. The mixed model analysis showed a significant main effect for response effector $(t=5.65)$ with faster hand responses than foot responses. A significant interaction between the factors adverb type and response effector emerged $(t=-4.68)$. Post hoc tests revealed significant differences for hand responses $(z=2.448, p=0.014)$ with faster hand responses following intensifying compared with attenuating adverbs. No difference emerged in the case of foot responses $(z=0.820, p=0.412)$. The interaction between verb and response effector was not significant $(t=-1.70)$. The three-way interaction of verb, response effector and adverb type was not significant $(t=0.82)$. All values are given in Table 2 . Fitted model parameters $( \pm S D)$ for verb $\mathrm{x}$ adverb type $\mathrm{x}$ response effector are depicted in Fig. 3B. 

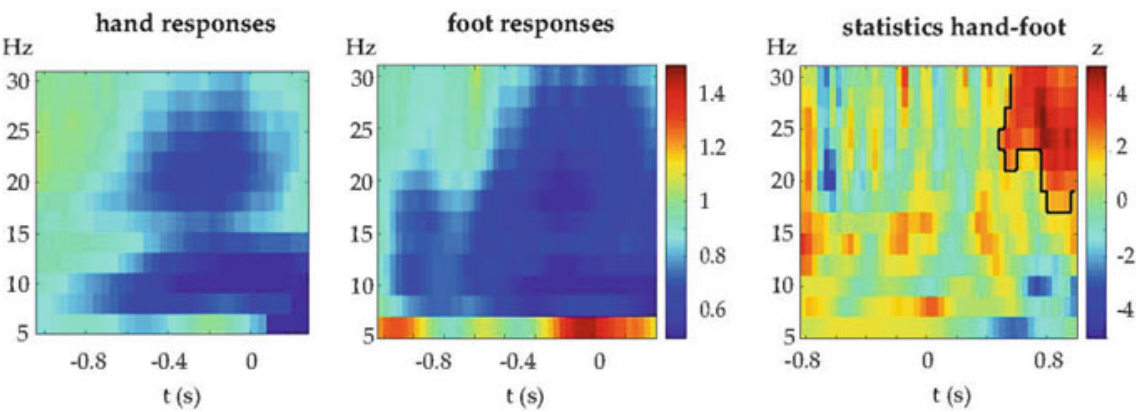

Fig. 4 Grandaverage EEG data and statistical contrasts relating to significant effects in the adverblocked analysis of Experiment 2. The time in seconds is depicted on the $\mathrm{x}$-axis with 0 denoting the onset of adverb, the frequency in Hertz is shown on the y-axis. Data is furthermore color-coded according to the power relative to baseline (left and middle column) or according to the $\mathrm{z}$-value (right column) of the respective statistical comparison. The contrast shows hand- and foot response-related activity in electrode $\mathrm{Cz}$ with the significant cluster outlined in black.

\subsubsection{EEG Data}

\section{Adverb-Locked Analysis}

A cluster between $t_{a}=0.48$ and $1 \mathrm{~s}$ after adverb onset $(p=0.003)$ indicated a significant difference between response effectors in the electrode $\mathrm{Cz}$ ranging from 17 to $30 \mathrm{~Hz}$, i.e. stronger beta desynchronization for foot responses (Fig. 4). No effect was found in $\mathrm{C} 3$ (all $p>0.201$ ). Neither adverbs nor any interaction with response effector or verb showed significant effects in electrodes $\mathrm{C} 3$ nor $\mathrm{Cz}$ (all $p>0.110$ ).

\section{Response-Locked Analysis}

A cluster at $t_{\mathrm{r}}=-0.16$ to $0.32 \mathrm{~s}(p<0.001)$ indicated a significant difference between hand and foot responses in electrode $\mathrm{C} 3$ ranging from 9 to $30 \mathrm{~Hz}$ showing stronger mu and beta desynchronization for hand responses (Fig. 5A). Complementarily, in electrode $\mathrm{Cz}$, a cluster indicated a significant difference between the hand and foot condition at $t_{\mathrm{r}}=0-0.4 \mathrm{~s}$ after response onset ( $\left.p=0.002\right)$ ranging from 15 to $30 \mathrm{~Hz}$, i.e. stronger beta desynchronization for foot responses (Fig. 5B). A significant cluster ( $p=0.019$ ) in electrode C3 showed that in the case of foot responses, the hand verb condition showed significantly more beta desynchronization than the foot verb condition at $t_{r}=-0.64$ to $0.16 \mathrm{~s}$ ranging from 12 to $18 \mathrm{~Hz}$ (Fig. 5C). No effect was observed in electrode $\mathrm{Cz}(p>0.082)$. No corresponding effect emerged for hand responses (all $p>0.116$ ). 
A

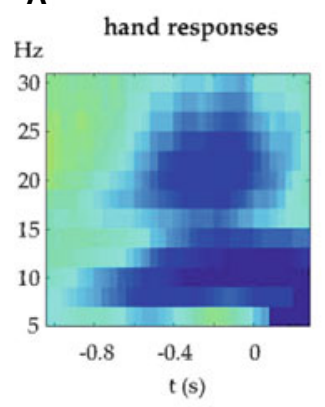

B

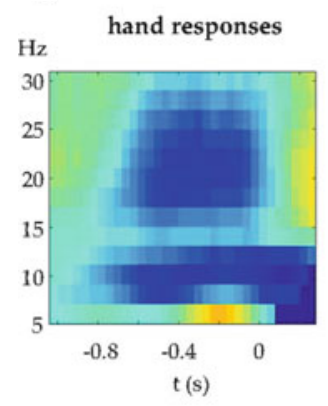

C

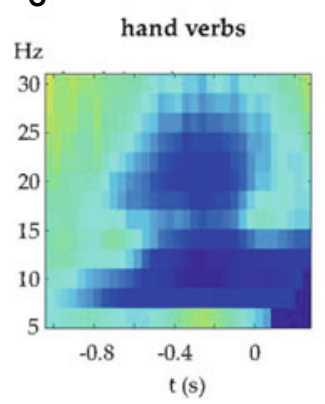

$\mathrm{C} 3$

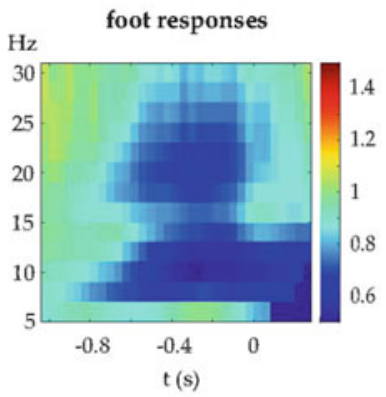

$\mathrm{Cz}$

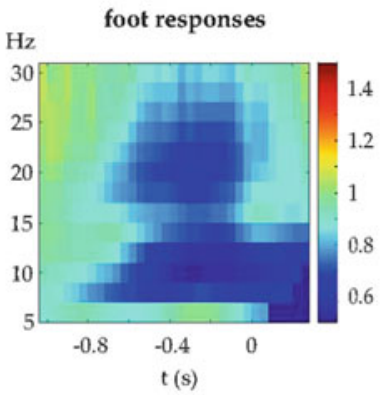

C3

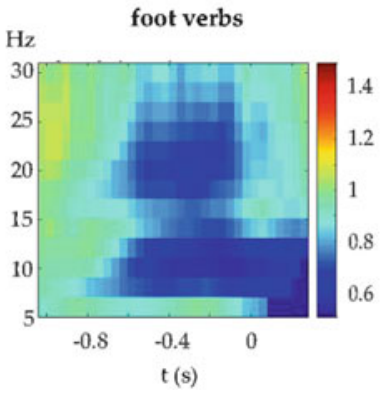

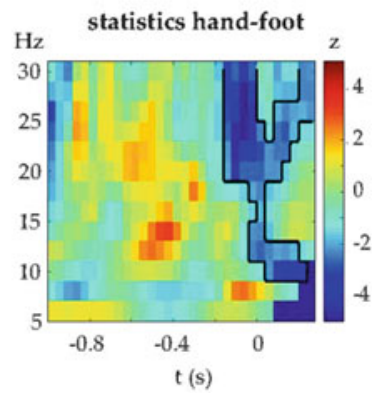
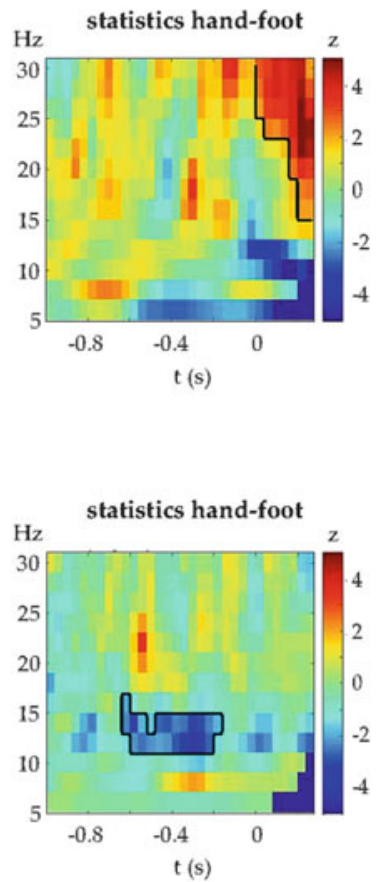

Fig. 5 Grandaverage EEG data and statistical contrasts relating to significant effects in the responselocked analysis of Experiment 2. The time in $\mathrm{s}$ is depicted on the $\mathrm{x}$-axis with 0 denoting the onset of response, the frequency in $\mathrm{Hz}$ is shown on the y-axis. Data is furthermore color-coded according to the power relative to baseline (left and middle column) or according to the z-value (right column) of the respective statistical comparison. A: Hand response- and foot response-related activity in electrode $\mathrm{C} 3$ with the significant cluster outlined in black. B: Hand response- and foot responserelated activity in electrode $\mathrm{Cz}$ with the significant cluster outlined in black. $\mathbf{C}$ : Foot response-related activity following hand verbs and foot verbs with the significant cluster outlined in black. 


\subsection{Discussion}

Our results show an influence of manner adverbs on motor behavior. In Experiment 1, we found a significant main effect of adverb indicating faster responses following intensifying compared with attenuating adverbs. This effect might depend on the direct relation between the force component of the action verb and the manner adverb specifying the amount of force implied in the movement (Goldschmidt et al., 2017). Action verbs are reported to elicit motor activation (Hauk et al., 2004; Pulvermüller, 2005), especially when processed semantically (Klepp et al., 2017; Sato et al., 2008). Motor output interacts with action-related language processing because of shared neuronal circuits (Boulenger et al., 2006; Dalla Volta et al., 2009). Manner adverbs modifying an action verb might therefore modulate its elicited motor activation by modulating the amount of force implied in the action. As was shown in the case of imageability (Klepp et al., 2015) and effector-specific movement (Klepp et al., 2017), semantic features of the action verb might influence motor behavior. Cortical motor areas might therefore also be involved in the processing of semantic features of stimuli relating to the action verb. This is furthermore corroborated by the complementary results of Experiment 2. Here, though no significant main effect of adverb type emerged, manner adverbs interacted with the response effector. Hand responses following intensifying adverbs were significantly faster than hand responses following attenuating adverbs. Participants had to respond depending on the adverb type.

Comparing Experiments 1 and 2 it seems that the main effect of adverb type in Experiment 1 switched to an interaction between adverb type and response effector in Experiment 2. The main difference between these two experiments is the order of adverb-verb (Experiment 1) and verb-adverb (Experiment 2) presentation combined with the instruction cues color change (Experiment 1) and adverb type (Experiment 2). The relevance and subsequent psycho-linguistic processing of the adverb for successfully operating on the tasks hence was different in Experiments 1 and 2: In Experiment 1, priming of force components could have taken place resulting in a main effect of adverb type even though the semantics of the adverbs were of minor relevance. In Experiment 2 on the other hand, the semantics of the adverb were indicative for the required response potentially resulting in simulation processes directly interacting with response preparation. In addition, while both tasks prompted semantic processing of the verbal material, Experiment 2 might have increased the participants' awareness of the semantic features of the manner by making them task-relevant. Studies concerning the mental timeline argued that mental simulations only occur during language processing, if the semantic features of the verbal material is task-relevant and the processor is aware of these features (Maienborn, Alex-Ruf, Eikmeier, \& Ulrich, 2015; Ulrich \& Maienborn, 2010). The increased awareness of the semantic features may have resulted in the more specific interaction between adverb and response. That the effect was only found for hand responses and not for foot responses might be attributable to the closer connection of the hand with language (Rizzolatti \& Arbib, 1998). Another explanation could be that due to 
longer response times for foot responses the interaction with adverbs might fade with processing time. Still, foot responses to intensifying adverbs were numerically faster than to attenuating adverbs. Arguably, intensifying adverbs might increase motor activation per se thereby increasing the motor contribution to the processing of the action verb. This might reflect a semantic priming effect even for manner adverbs. This remains elusive, however, since no corresponding effect of manner adverbs was found in the neurophysiological data of Experiment 2. Differential motor activation relating to intensifying and attenuating adverbs could arise in studies focusing solely on the semantic processing of manner adverbs. Yet both experiments reported in this study incorporated manner adverb-action verb combinations which might have limited our ability to discern adverb- and verb-related processes regarding brain oscillations.

In addition to the effects of manner adverbs, action verbs interacted with motor behavior. In Experiment 1, facilitated hand and foot responses in congruent compared with incongruent verb-response combinations revealed a semantic priming effect, which is in line with previous findings (Scorolli \& Borghi, 2007; Klepp et al., 2017). This is corroborated by the neurophysiological data recorded in Experiment 2. Results showed reduced beta desynchronization in electrode $\mathrm{C} 3$ for foot responses following foot verbs compared to hand verbs. As expected, the congruent condition presented with reduced motor activation (Grisoni et al., 2016; Schacter et al., 2007). The onset of the effect was about $600 \mathrm{~ms}$ before response onset, which would have allowed the action verb to be processed semantically and subsequently interacting with response execution (Kutas \& Hillyard, 1984). However, the effect emerged in electrode C3 only, which was located approximately above the cortical motor hand area, whereas no complementary effect for hand responses emerged in electrode $\mathrm{Cz}$. Furthermore, no verb $\mathrm{x}$ response effector interaction was visible in the behavioral data of Experiment 2 . Hence, the observed differences might alternatively be accounted for by significant differences between hand and foot verbs, respectively. This might be due to the limited set of action verbs employed in this study. To reduce confounding effects of imageability, familiarity and frequency, we matched our verb set very carefully. However, this might have prevented us from mapping a wider range of possible differences in the action verbs, for instance with regard to their movement pattern as well as other linguistic features. Differences in brain oscillations for foot responses following hand and foot verbs might therefore alternatively be unrelated to a semantic priming effect but merely reflect an overall stronger desynchronization following hand verbs compared with foot verbs independent of the response effector.

Two further aspects should be discussed, namely the somatotopy of response effectors and timing. Hand and foot responses were required in a double-dissociation paradigm. As visible in the behavioral data of both experiments, hand responses were overall faster than foot responses, which is in line with previous findings (Buccino et al., 2005; Gianelli \& Dalla Volta, 2015; Klepp et al., 2017). Experiment 2 indicated differential motor activation for hand and foot responses in electrodes C3 and $\mathrm{Cz}$ in analyses around adverb and response onset. Oscillatory differences arose predominantly in the beta frequency range in a time window relating to response execution. Crucially, stronger desynchronization for hand responses was observed 
in electrode $\mathrm{C} 3$, while stronger desynchronization for foot responses emerged in electrode $\mathrm{Cz}$. Our results thus demonstrate somatotopical activity differences related to the respective response effector, as hypothesized. This should have allowed for the detection of differential EEG effects of verbs and adverbs for the two response effectors. Indeed, stronger desynchronization for hand than foot verbs preceding foot responses in electrode $\mathrm{C} 3$ was found, but not the full pattern of effects expected from the double dissociation paradigm. One straightforward explanation may be that when no behavioral effects were found, there simply might have been no differences in neurophysiological processing to be measured by EEG. Note, however, that neurophysiological effects are sometimes reported in the absence of behavioral differences (Mollo, Pulvermüller, \& Hauk, 2016). Nevertheless, the paradigm of Experiment 2 may be not optimally suited for the detection of language-motor priming effects. More specifically, the temporal proximity between manner adverb and hand/foot responses onset in Experiment 2 might have been too close to discern oscillatory differences in the semantic processing of manner adverbs. Instead, potentially subtle activity differences relating to the processing of the manner adverb might have been overshadowed by motor activation induced during response execution processes. In addition, potential activation differences might have been observable in other electrodes, especially located above other language-related brain areas, e.g. temporal regions; these regions might also reflect differences based on the type of manner adverb or its interaction with action verbs.

An important concern in the comparison between the effects of Experiment 1 and Experiment 2 is the temporal structure of stimulus presentation and the average response time. In Experiment 1, the average time interval between adverb and response onset was $1300 \mathrm{~ms}$ while the average time interval between action verb and response, on the other hand, was only $900 \mathrm{~ms}$. There was a priming effect of verb effector, but only an unspecific effect of adverb type. Thus, Experiment 2 was designed to induce more semantic interaction with the hypothesis to find an interaction of priming and adverb type, reflected in neurophysiological data. The reversal of verb and adverb presentation order also implied that the average time interval between verb presentation and response was $1150 \mathrm{~ms}$, with $750 \mathrm{~ms}$ between adverb and response onset. Action verbs did not influence response times possibly due to the prolonged interval between verb and response onset. Accordingly, stimulus-response intervals likely modulated the effects observed in the two experiments.

Further, a relatively small sample size and the inclusion of only two EEG electrodes in the statistical analyses might have limited the power of our results. Inclusion of a greater sample to increase effect sizes and a greater number of EEG electrodes could lead to a more detailed picture regarding the interplay of action-related language processing and motor activity and its modulation by manner adverbs.

Future studies should furthermore investigate which semantic aspects of manner adverbs potentially elicit motor activation, e.g. differentiating between force and velocity, providing closer insights into the extent of motor involvement in language processing. The small number of force- and velocity-modulating adverbs (two each for intensifying and attenuating adverbs) prevented us from validly deducing differential effects on the verb-response interaction. On the other hand, some action verbs, 
e.g. "boxen" (to box), might be predominately modulated by adverbs defining the amount of force, while others, e.g. "tippen" (to type), might be more susceptible to an adverbial modulation relating to the velocity of the action. This raises the important question whether such differences are mirrored in the overt motor behavior or neurophysiological activity. Additionally, previous studies suggested an influence of various movement-dependent factors on beta-desynchronization in motor areas (Tan et al., 2013; Nakayashiki, Saeki, Takata, Hayashi, \& Kondo, 2014). A consecutive study might therefore also be concerned with the influence of manner adverb on the motor response by taking various movement-related parameters into consideration. Furthermore, adverb-verb combinations should be included in natural sentences to shed more light on the influence of grammatical constructions on action-related language processing in sensorimotor areas.

Taken together, our study provides an indication that manner adverbs influence motor behavior while corroborating the already existing data concerning the interaction between action verb processing and motor output. These findings are in line with assumptions made by embodied cognition theories proposing an essential role of sensorimotor areas in the processing and storage of action concepts inherent in action-related language. The adverbial modulation of motor behavior might reflect a certain variation of motor involvement in language processing. This involvement could be susceptible to grammatical constructions modifying the action component of action verbs. Yet, effects of the verb material in a closely matched verb set and influences of timing have to be taken into account.

Acknowledgements This work was supported by the German Research Foundation (Deutsche Forschungsgemeinschaft). We thank Fabian Friedrich for the initial preparation of adverb stimuli, Anja Goldschmidt (SFB991/B09) and Thomas Gamerschlag (SFB991/Z) for linguistic advice, Tim Seuchter (SFB991-I-03/-II-B03) and Matthias Sure (SFB991/B03) for collecting parts of the data and Peter Indefrey (SFB991/A04, C03) for sharing expertise about priming experiments.

\section{References}

Andres, M., Finocchiaro, C., Buiatti, M., \& Piazza, M. (2015). Contribution of motor representations to action verb processing. Cognition, 134, 174-184. https://doi.org/10.1016/j.cognition.2014. 10.004.

Aziz-Zadeh, L., Wilson, S. M., Rizzolatti, G., \& Iacobini, M. (2006). Congruent embodied representations for visually presented actions and linguistic phrases describing actions. Current Biology, 16, 1818-1823. https://doi.org/10.1016/j.cub.2006.07.060.

Baayen, R. H., Davidson, D. J., \& Bates, D. M. (2008). Mixed-effects modeling with crossed random effects for subjects and items. Journal of Memory and Language, 59, 390-412. https://doi.org/ 10.1016/j.jml.2007.12.005.

Bak, T. H., O’Donovan, D. G., Xuereb, J. H., Boniface, S., \& Hodges, J. R. (2001). Selective impairment of verb processing associated with pathological changes in Brodmann areas 44 and 45 in the motor neurone disease-dementia-aphasia syndrome. Brain, 124, 103-120. https://doi. org/10.1093/brain/124.1.103. 
Barsalou, L. W. (2008). Grounded cognition. Annual Review Psychology, 59, 617-645. https://doi. org/10.1146/annurev.psych.59.103006.093639.

Bates, D. M., Maechler, M., Bolker, B., \& Walker, S. (2015). Fitting linear mixed-effects models using lme4. Journal of Statistical Software, 67(1), 1-48. https://doi.org/10.18637/jss.v067.i01.

Biemann, C., Heyer, G., Quasthoff, U., \& Richter, M. (2007). The Leipzig Corpora CollectionMonolingual corpora of standard size. In Proceedings of Corpus Linguistics 2007. Birmingham, UK.

Binder, J. R., \& Desai, R. H. (2011). The neurobiology of semantic memory. Trends in Cognitive Sciences, 15(11), 527-536. https://doi.org/10.1016/j.tics.2011.10.001.

Boulenger, V., Hauk, O., \& Pulvermüller, F. (2009). Grasping ideas with the motor system: Semantic somatotopy in idiom comprehension. Cerebral Cortex, 19, 1905-1914. https://doi.org/10.1093/ cercor/bhn217.

Boulenger, V., Roy, A. C., Paulignan, Y., Deprez, V., Jeannerod, M., \& Nazir, T. A. (2006). Cross-talk between language process and overt motor behavior in the First $200 \mathrm{msec}$ of processing. Journal of Cognitive Neuroscience, 18, 1607-1615. https://doi.org/10.1162/jocn.2006.18.10.1607.

Buccino, G., Riggio, L., Melli, G., Binkofski, F., Gallese, V., \& Rizzolatti, G. (2005). Listening to action-related sentences modulates the activity of the motor system: A combined TMS and behavioral study. Cognitive Brain Research, 24, 355-363. https://doi.org/10.1016/j.cogbrainres. 2005.02.020.

Dalla Volta, R., Gianelli, C., Campione, G. C., \& Gentilucci, M. (2009). Action word understanding and overt motor behavior. Experimental Brain Research, 196(3), 403-412. https://doi.org/10. 1007/s00221-009-1864-8.

de Vega, M., Léon, I., Hernández, J. A., Valdés, M., Padrón, I., \& Ferstl, E. C. (2014). Action sentences activate sensory motor regions in the brain independently of their status of reality. Journal of Cognitive Neuroscience, 26(7), 1363-1376. https://doi.org/10.1162/jocn_a_00559.

Ehrenstein, W. H., \& Arnold-Schulz-Gahmen, B. E. (1997). Auge, Ohr, Hand und Fuß: Bestimmung des individuellen Lateralitätsprofils. Dortmund: Institut für Arbeitsphysiologie.

Fernandino, L., Conant, L. L., Binder, J. R., Blindauer, K., Hiner, B., Spangler, K., et al. (2013). Parkinson's disease disrupts both automatic and controlled processing of action verbs. Brain and Language, 127, 65-74. https://doi.org/10.1016/j.bandl.2012.07.008.

Gianelli, C., \& Dalla Volta, R. (2015). Does listening to action-related sentences modulate the activity of the motor system? Replication of a combined TMS and behavioral study. Frontiers in Psychology, 5(1511). https://doi.org/10.3389/fpsyg.2014.01511.

Glenberg, A. M., \& Kaschak, M. P. (2002). Grounding language in action. Psychonomic Bulletin \& Review, 9(3), 558-565. https://doi.org/10.3758/BF03196313.

Goldschmidt, A., Gamerschlag, T., Petersen, W., Gabrovska, E., \& Geuder, W. (2017). Towards verb modification in frames. In H. Hansen, S. Murray, M. Sadrzadeh. \& H. Zeevat (Eds.), Logic, language, and computation. TbiLLC 2015. Lecture Notes in Computer Science (Vol. 10148). Springer, Berlin, Heidelberg. https://doi.org/10.1007/978-3-662-54332-02.

Grisoni, L., Dreyer, F. R., \& Pulvermüller, F. (2016). Somatotopic semantic priming and prediction in the motor system. Cerebral Cortex, 26, 2353-2366. https://doi.org/10.1093/cercor/bhw026.

Grossman, M., Anderson, C., Khan, A., Avants, B., Elman, L., \& McCluskey, L. (2008). Impaired action knowledge in amyotrophic lateral sclerosis. Neurology, 71, 1396-1401. https://doi.org/10. 1212/01.wnl.0000319701.50168.8c.

Hauk, O., Johnsrude, I., \& Pulvermüller, F. (2004). Somatotopic representation of action words in human motor and premotor cortex. Neuron, 41, 301-307. https://doi.org/10.1016/S0896-627 3(03)00838-9.

Hauk, O., \& Pulvermüller, F. (2004). Neurophysiological distinction of action words in the frontocentral cortex. Human Brain Mapping, 21, 191-201. https://doi.org/10.1002/hbm.10157.

Herrera, E., Rodríguez-Ferreiro, J., \& Cuetos, F. (2011). The effect of motion content in action naming by Parkinson's disease patients. Cortex, 48(7), 900-904. https://doi.org/10.1016/j.cor tex.2010.12.007. 
Kemmerer, D., Castillo, J. G., Talavage, T., Patterson, S., \& Wiley, C. (2008). Neuroanatomical distribution of five semantic components of verbs: Evidence from fMRI. Brain and Language, 107, 16-43. https://doi.org/10.1016/j.bandl.2007.09.003.

Kiefer, M., \& Pulvermüller, F. (2011). Conceptual representations in mind and brain: Theoretical developments, current evidence and future directions. Cortex, 48(7), 805-825. https://doi.org/10. 1016/j.cortex.2011.04.006.

Klepp, A., Niccolai, V., Buccino, G., Schnitzler, A., \& Biermann-Ruben, K. (2015). Languagemotor interference reflected in MEG beta oscillations. Neuroimage, 109, 438-448. https://doi. org/10.1016/j.neuroimage.2014.12.077.

Klepp, A., Niccolai, V., Sieksmeyer, J., Arnzen, S., Indefrey, P., Schnitzler, A., et al. (2017). Bodypart specific interactions of action verb processing with motor behaviour. Behavioural Brain Research, 328, 149-158. https://doi.org/10.1016/j.bbr.2017.04.002.

Klepp, A., Weissler, H., Niccolai, V., Terhalle, A., Geisler, H., Schnitzler, A., et al. (2014). Neuromagnetic hand and foot motor sources recruited during action verb processing. Brain and Language, 128, 41-52. https://doi.org/10.1016/j.bandl.2013.12.001.

Kutas, M., \& Hillyard, S. A. (1984). Brain potentials during reading reflect word expectancy and semantic association. Nature, 307, 161-163. https://doi.org/10.1038/307161a0.

Lange, J., Oostenveld, R., \& Fries, P. (2011). Perception of the touch-induced visual doubleflash illusion correlates with changes of rhythmic neuronal activity in human visual and somatosensory areas. Neuroimage, 54, 1395-1405. https://doi.org/10.1016/j.neuroimage.2010.09.031.

Lenth, R. V. (2016). Least-squares means: The R package 1smeans. Journal of Statistical Software, 69(1), 1-33. https://doi.org/10.18637/jss.v069.i01.

Maienborn, C., Alex-Ruf, S., Eikmeier, V., \& Ulrich, R. (2015). Do we map remembrances to the left/back and expectations to the right/front of a mental timeline? Space-time congruency effects with retrospective and prospective verbs. Acta Psychologica, 156, 168-178. https://doi.org/10. 1016/j.actpsy.2014.11.006.

Maris, E., \& Oostenveld, R. (2007). Nonparametric statistical testing of EEG- and MEGdata. Journal of Neuroscience Methods, 164, 177-190. https://doi.org/10.1016/j.jneumeth.2007. 03.024 .

Meteyard, L., Rodriguez Cuadrado, S., Bahrami, B., \& Vigliocco, G. (2012). Coming of age: A review of embodiment and the neuroscience of semantics. Cortex, 48, 788-804. https://doi.org/ 10.1016/j.cortex.2010.11.002.

Mollo, G., Pulvermüller, F., \& Hauk, O. (2016). Movement priming of EEG/MEG brain responses for action-words characterizes the link between language and action. Cortex, 74, 262-276. https:// doi.org/10.1016/j.cortex.2015.10.021.

Moody, C. L., \& Gennari, S. P. (2010). Effects of implied physical effort in sensory-motor and pre-frontal cortex during language comprehension. NeuroImage, 49, 782-793. https://doi.org/10. 1016/j.neuroimage.2009.07.065.

Moreno, I., de Vega, M., Léon, I., Bastiaansen, M., Lewis, A. G., \& Magyari, L. (2015). Brain dynamics in the comprehension of action-related language. A time-frequency analysis of mu rhythms. Neuroimage, 109, 50-62. https://doi.org/10.1016/j.neuroimage.2015.01.018.

Nakayashiki, K., Saeki, M., Takata, Y., Hayashi, Y., \& Kondo, T. (2014). Modulation of event-related desynchronization during kinematic and kinetic hand movements. Journal of Neuroengineering and Rehabilitation, 11(1), 90. https://doi.org/10.1186/1743-0003-11-90.

Niccolai, V., Klepp, A., Weissler, H., Hoogenboom, N., Schnitzler, A., \& Biermann-Ruben, K. (2014). Grasping hand verbs: Oscillatory beta and alpha correlates of action-word processing. PLOS ONE, 9(9), e108059. https://doi.org/10.1371/journal.pone.0108059.

Oldfield, R. C. (1971). The assessment and analysis of handedness: The Edinburgh inventory. Neuropsychologia, 9, 97-113. https://doi.org/10.1016/0028-3932(71)90067-4.

Oostenveld, R., Fries, P., Maris, E., \& Schoffelen, J. M. (2011). Fieldtrip: open source software for advanced analysis of MEG, EEG, and invasive electrophysiological data. Computational Intelligence and Neuroscience, 2011. https://doi.org/10.1155/2011/156869. 
Perniss, P., \& Vigliocco, G. (2014). The bridge of iconicity: from a world of experience to the experience of language. Philosophical Transactions of the Royal Society B, 369(1651), 20130300. https://doi.org/10.1098/rstb.2013.0300.

Pfurtscheller, G., \& Lopes da Silva, F. H. (1999). Event-related EEG/MEG synchronization and desynchronization: basic principles. Clinical Neurophysiology, 110, 1842-1857. https://doi.org/ 10.1016/S1388-2457(99)00141-8.

Pfurtscheller, G., Neuper, C., Andrew, C., \& Edlinger, A. G. (1997). Foot and hand area mu rhythms. International Journal of Psychophysiology, 26, 121-135. https://doi.org/10.1016/S0167-876 0(97)00760-5.

Postle, N., McMahon, K. L., Ashton, R., Meredith, M., \& de Zubicaray, G. I. (2008). Action word meaning representations in cytoarchitectonically defined primary and premotor cortices. Neuroimage, 43, 634-644. https://doi.org/10.1016/j.neuroimage.2008.08.006.

Pulvermüller, F. (2005). Brain mechanisms linking language and action. Nature Reviews Neuroscience, 6, 576-582. https://doi.org/10.1038/nrn1706.

Pulvermüller, F. (2018). Neural reuse of action perception circuits for language, concepts and communication. Progress in Neurobiology, 160, 1-44. https://doi.org/10.1016/j.pneurobio.2017. 07.001 .

Pulvermüller, F., Härle, M., \& Hummel, F. (2000). Neurophysiological distinction of verb categories. NeuroReport, 11(12), 2789-2793.

Pulvermüller, F., Härle, M., \& Hummel, F. (2001). Walking or talking? Behavioral and neurophysiological correlates of action verb processing. Brain \& Language, 78, 143-168. https://doi.org/ $10.1006 /$ brln.2000.2390.

Rizzolatti, G., \& Arbib, M. A. (1998). Language within our grasp. Trends in Neuroscience, 21(5), 188-194. https://doi.org/10.1016/S0166-2236(98)01260-0.

Rüschemeyer, S. A., Lindemann, O., van Rooij, D., van Dam, W., \& Bekkering, H. (2010). Effects of intentional motor actions on embodied language processing. Experimental Psychology, 57(4), 260-266. https://doi.org/10.1027/1618-3169/a000031.

Sato, M., Mengarelli, M., Riggio, L., Gallese, V., \& Buccino, G. (2008). Task related modulation of the motor system during language processing. Brain and Language, 105, 83-90. https://doi. org/10.1016/j.bandl.2007.10.001.

Schacter, D. L., Wig, G. S., \& Stevens, W. D. (2007). Reductions in cortical activity during priming. Current Opinion in Neurobiology, 17(2), 171-176. https://doi.org/10.1016/j.conb.2007.02.001.

Scorolli, C., \& Borghi, A. M. (2007). Sentence comprehension and action: Effector specific modulation of the motor system. Brain Research, 1130, 119-124. https://doi.org/10.1016/j.brainres. 2006.10.033.

Steingrüber, H. J. (2011). Hand-Dominanz-Test. Göttingen: Hogrefe.

Tan, H., Pogosyan, A., Anzak, A., Ashkan, K., Bogdanovic, M., Green, A. L., et al. (2013). Complementary roles of different oscillatory activities in the subthalamic nucleus in coding motor effort in Parkinsonism. Experimental Neurology, 248, 187-195. https://doi.org/10.1016/j.expneurol.2013. 06.010 .

Taylor, L. J., \& Zwaan, R. A. (2008). Motor resonance and linguistic focus. The Quarterly Journal of Experimental Psychology, 61(6), 896-904. https://doi.org/10.1080/17470210701625519.

Tettamanti, M., Buccino, G., Saccuman, M. C., Gallese, V., Danna, M., Scifo, P., et al. (2005). Listening to action-related sentences activates fronto-parietal motor circuits. Journal of Cognitive Neuroscience, 17(2), 273-281.

Ulrich, R., \& Maienborn, C. (2010). Left-right coding of past and future in language. The mental timeline during sentence processing. Cognition, 117, 126-138. https://doi.org/10.1016/j.cognit ion.2010.08.001.

van Dam, W. O., Rüschemeyer, S. A., \& Bekkering, H. (2010). How specifically are action verbs represented in the neural motor system: An fMRI study. Neuroimage, 53, 1318-1325. https://doi. org/10.1016/j.neuroimage.2010.06.071. 
van Dijk, H., Nieuwenhuis, I. L., \& Jensen, O. (2010). Left temporal alpha band activity increases during working memory retention of pitches. European Journal of Neuroscience, 31, 1701-1707. https://doi.org/10.1111/j.1460-9568.2010.07227.x.

van Elk, M., van Schie, H. T., Zwaan, R. A., \& Bekkering, H. (2010). The functional role of motor activation in language processing: Motor cortical oscillations support lexical-semantic retrieval. Neuroimage, 50, 665-677. https://doi.org/10.1016/j.neuroimage.2009.12.123.

Yang, J., \& Shu, H. (2011). Embodied representation of tool-use action verbs and hand action verbs: Evidence from a tone judgement task. Neuroscience Letters, 493, 112-115. https://doi.org/10. 1016/j.neulet.2011.02.020.

Open Access This chapter is licensed under the terms of the Creative Commons Attribution 4.0 International License (http://creativecommons.org/licenses/by/4.0/), which permits use, sharing, adaptation, distribution and reproduction in any medium or format, as long as you give appropriate credit to the original author(s) and the source, provide a link to the Creative Commons license and indicate if changes were made.

The images or other third party material in this chapter are included in the chapter's Creative Commons license, unless indicated otherwise in a credit line to the material. If material is not included in the chapter's Creative Commons license and your intended use is not permitted by statutory regulation or exceeds the permitted use, you will need to obtain permission directly from the copyright holder. 